\title{
Untreated depression in the first trimester of pregnancy leads to postpartum depression: high rates from a natural follow-up study
}

This article was published in the following Dove Press journal:

Neuropsychiatric Disease and Treatment

19 February 2015

Number of times this article has been viewed

\author{
Esra Yazici' \\ Tulay Sati Kirkan² \\ Puren Akcali Aslan ${ }^{3}$ \\ Nazan Aydin ${ }^{4}$ \\ Ahmet Bulent Yazici' \\ 'Department of Psychiatry, Faculty \\ of Medicine, Sakarya University, \\ Adapazarı, Turkey; ${ }^{2}$ Bolge Training \\ and Research Hospital, Erzurum, \\ Turkey; ${ }^{3}$ Adana Training and Research \\ Hospital, Adana, Turkey; ${ }^{4}$ Bakirkoy \\ Nervous and Mental Disease \\ Education and Research Hospital, \\ Istanbul, Turkey
}

Background: This is a natural follow-up study that presents the postpartum results of women who experienced depression during pregnancy.

Methods: This study involved 78 women diagnosed with depression in the first trimester of pregnancy. All patients were diagnosed using the Structured Clinical Interview for DSM-IV Axis I Disorders (SCID-I) in the first trimester and all were referred to a psychiatric center for treatment. Of the 78, 73 were contacted postpartum and reassessed by SCID-I. Treatment anamnesis was evaluated retrospectively.

Results: The women were divided into two groups at the postpartum evaluation according to anamnesis of psychiatric treatment. Twenty-one of the 73 (28.7\%) had received treatment during pregnancy (treated group). Fifty-two women had not been treated (untreated group). In the treated group, no postpartum depression was determined $(0 \%)$. In the untreated group, $92 \%(n=48)$ of women had a depressive disorder postpartum $(P<0.01)$. In addition, scores regarding depression, functionality, and perceived social support were worse postpartum for the untreated group.

Conclusion: Untreated depression during pregnancy is an important predictor of postpartum depression. This natural follow-up study is important because it presents very striking rates of postpartum depression. Referral of patients with depression during pregnancy to psychiatric treatment should be provided and is strongly encouraged.

Keywords: untreated depression, pregnancy, postpartum, perinatal, depression, mood

\section{Introduction}

Depression during pregnancy and postpartum is important because it involves both mother and baby as well as all people with whom they interact in the community. ${ }^{1}$ Antenatal depression has been associated with low maternal weight gain; increased frequency of cigarette, alcohol, and substance use ${ }^{2}$ and negative emotions and thoughts about the pregnancy and the baby. ${ }^{3}$ In addition, depression in pregnant mothers may alter the pattern of brain development in their babies. ${ }^{4}$ The prevalence of depressive symptoms in pregnancy has been reported to be $12 \%-36 \%$ in Turkey. ${ }^{5}$

Women and their babies are at risk due to depression not only during pregnancy, but also after the birth. Women in the postnatal period, which includes the breastfeeding period and 1 year after childbirth, have a significantly higher risk of psychiatric disorders, with a retrospective study showing the risk to be three to four times higher postpartum than during pregnancy. ${ }^{6}$ Although childbearing is usually a positive and satisfying experience, some new mothers may experience negative emotions, such as depression. $^{7}$ Perinatal depression rates of $5 \%-30 \%$ and $20 \%$ have been reported in developed and developing countries, respectively. ${ }^{8}$ In a naturalistic longitudinal study conducted with 1,066 pregnant women, the prevalence of depression was found to
Correspondence: Esra Yazici

Department of Psychiatry, Faculty

of Medicine, Sakarya University, Korucuk,

Adapazarı, Sakarya, 54000, Turkey

Tel +905333870679

Email dresrayazici@yahoo.com 
be $12.4 \%$ in pregnancy and $9.6 \%$ in the postpartum period. ${ }^{9}$ In studies conducted in Eastern Turkey, the depression rate in a prevalence study was found to be $15 \%$ in the first trimester of pregnancy and $35 \%$ in the postnatal period in a follow-up study. ${ }^{10,11}$

Previous studies have shown that prior depression is a risk factor for developing depression during pregnancy and in the postnatal period. ${ }^{12}$ A study by Kirkan et al showed that one of the most important risk factors for postnatal depression was having been depressed at some time in the past. ${ }^{11}$

It has been known for years that depression during pregnancy is a risk factor for both mothers and babies, yet these patients do not receive adequate treatment. One study showed that even psychiatrists who who work in this area are uneasy about treating depression during pregnancy. ${ }^{1}$ Even today, there are studies that conclude that leaving depression untreated during pregnancy is the proper option. ${ }^{13}$

It is now known that depression in pregnancy is a risk factor for postpartum depression. But what is the risk? This study is a natural observational follow-up study with striking results that provide answers to two questions: what will happen if a mother experiencing depression during pregnancy is treated, and what will happen if she is not?

\section{Methods}

This study presents data regarding women experiencing depression in the first trimester of pregnancy. The women had been determined to have depressive disorders in a previously conducted screening ${ }^{10}$ and were involved to join the follow-up study. ${ }^{11}$ Previous articles by Akçalı Aslan et al ${ }^{10}$ and Kirkan et $\mathrm{al}^{11}$ presented data about the prevalence of depression in the first trimester of pregnancy in Erzurum, Turkey, where the screening and follow-up study were conducted.

The previously conducted screening and follow-up study were parts of a scanning study. The study used the Edinburgh Postpartum Depression Scale (EPDS) to assess 463 pregnant women in the first trimester of pregnancy. In addition, those above a certain breakpoint (EPDS scores of 11-12) were assessed by the Structured Clinical Interview for DSM-IV Axis I Disorders (SCID-I), Clinical Version (SCID-CV); the General Health Questionnaire (GHQ); and the General Assessment of Functionality (GAF). During the scanning study, 78 women who were diagnosed with depressive disorders were referred to the psychiatry polyclinic for treatment. A follow-up study of postpartum depression ${ }^{11}$ was conducted using the same sample, with 360 women that could be contacted in the postpartum period. During the follow-up study, 73 women who were depressive during the first trimester of pregnancy were contacted postpartum and assessed using the same scales. In the present study, those 73 women were evaluated with a form that registered sociodemographic data and treatment anamnesis with regard to the pregnancy and postnatal periods.

The study had local governmental ethics committee approval, and it conforms to the provisions of the Declaration of Helsinki (as revised in Edinburgh, Scotland in 2000). Written consent was obtained from the women before both the pregnancy period and postpartum period evaluations.

The sociodemographic data form was prepared by our team in conformance with the purpose of the study, and it asked for information such as the age and education level of the patient. It was filled in by the physician based on the patients' statements.

The SCID-CV is a semi-structured diagnostic interview chart whose Turkish translation and validity/reliability testing were performed by Corapçıglu et al. ${ }^{14}$ It contains DSM-IV diagnoses. The SCID-I begins with a sociodemographic data guide and covers seven diagnosis groups: mood disorders, psychotic disorders, alcohol and substance-related disorders, anxiety disorders, somatoform disorders, eating disorders, and adjustment disorders. It has high reliability for psychiatric disorders. It is used as a standard interview to affirm diagnoses in clinical studies.

The Edinburgh Postnatal Depression Scale (EPDS) was used to identify women with depression. ${ }^{15}$ In many parts of the world, postnatal screening for significant distress and depression is undertaken using the EPDS. The EPDS is a tenitem, self-reported questionnaire. Scores range from 0 to 30 , with higher scores implying greater distress. This scale was translated into Turkish and tested for reliability in Turkish women by Engindeniz et al who determined that its sensitivity and specificity were $84 \%$ and $88 \%$, respectively. Cronbach's alpha was 0.79 when the cut-off value was accepted as $12 / 13 .{ }^{16}$ In addition, the results of another validation study ${ }^{17}$ were as follows: sensitivity $=75.5 \%$, specificity $=71.5 \%$, positive predictive value $=30.3 \%$, negative predictive value $=94.5 \%$, and Cronbach's alpha value $=0.72$ as compared to the SCID-I when a cut-off score of 12 was used. Therefore, women with scores of 13 and over were included in the group with depression.

The GHQ-28 is a self-administered screening test for detecting poor mental health in the general population. Since its development by Goldberg in the 1970 s, ${ }^{18}$ this questionnaire has been widely used in many countries for detecting psychological morbidity. Subjects are asked to think about their health over the past few weeks and answer the questions accordingly. There are four response options for each item ("better than usual", "same as usual", "less than usual", "much 
less than usual"). Higher scores indicate poorer psychological health. The original questionnaire comes in a 12-question and a 28 -question version. ${ }^{18,19}$ During Turkish validity and reliability study, these versions were combined into a 34-item version (with six items that were common to both original versions). ${ }^{20}$ This study used the 28-item version.

The GAF is a clinician's rating referring to the patient's overall level of functioning. Ratings can range from 1 (severe impairment) to 100 (good general functioning). The GAF scale was included in the translation of the Turkish version of SCID-I-CV, ${ }^{14}$ but an individual reliability study of this instrument has not been carried out with a Turkish sample.

The Perceived Social Support from Friends and Family Scale (PSS-Fr and PSS-Fa) measures perceived social support and has two subscales (for familiy and for friends). The scales were developed by Procidano and Heller ${ }^{21}$ and translated into Turkish by Eskin. ${ }^{22}$ Reported Cronbach's alpha coefficients in a Turkish population were 0.85 for the PSS-Fa and 0.75 for the PSS-Fr. ${ }^{22}$ Each scale contains 20 items that are marked either "true", "false", or "don't know". This study used the PSS-Fa subscale.

\section{Statistical analysis}

In this study, a comparison of continuous variables was performed with independent samples using a Student's $t$-test. The significance level for the tests was established at $P \leq 0.05$. A chi-square test was conducted for categorical variables. Correlation analysis was used to determine the relationship among linear variables. All analyses were carried out using SPSS statistical software, version 17.0.

\section{Results}

This study included 78 women who were diagnosed with depression during a depression-scanning study, which had involved women in the Erzurum city center who were in their first trimester of pregnancy and then the postpartum period. ${ }^{10,11}$ In the first evaluation, during the first trimester of pregnancy, 78 women were determined to have depressive disorder, including major depressive disorder $(n=57)$, double depression $(\mathrm{n}=7)$, minor depressive disorder $(\mathrm{n}=12)$, and dysthymia $(\mathrm{n}=2)$. None had severe depression that required hospitalization; all were referred to a psychiatry outpatient clinic for treatment.

Of these women, 73 were contacted again during the postnatal period. The average age of the participants in the study was $28.26 \pm 5.81(17-43)$ years. The majority (54.4\%) had less than 8 years of education. All were married, and the average number of children was $2.30 \pm 1.05$ (1-6).

At postpartum evaluation, the women were divided into two groups according to anamnesis of psychiatric treatment. Of the 73 women, 21 (28.7\%) had received treatment during pregnancy, including $32.1 \%$ who were diagnosed with major depressive disorders (treated group). Fifty-two of the 73 women had not been treated (untreated group). In the treated group, no postpartum depression was determined $(0 \%)$. In the untreated group, $92 \%(n=48)$ of women who had experienced depression during the first trimester had a depressive disorder during the postpartum period $(P<0.01)$. Table 1 shows the subgroups of depression.

The mean age of onset of depression for the whole sample was $27.74 \pm 5.24$ years, with $27.65 \pm 5.64$ years for the untreated group and $27.95 \pm 4.22$ years for the treated group. None of the patients had severe depression or comorbid psychiatric diseases. Five of the patients in the untreated group had a diagnosis of previous depression, as did two of the patients in the treated group ( $P>0.05$ for comparison of groups).

The difference between the EPDS scores, which were used to measure depression during pregnancy and postnatal periods, of the untreated and treated groups was significant. In addition, the postnatal scores of the untreated group were significantly higher when compared to the prenatal scores.

Table I SCID-I diagnoses of treated and untreated women in the first trimester of pregnancy and the postpartum period

\begin{tabular}{lllll}
\hline Diagnosis & $\begin{array}{l}\text { Treated group } \\
(\mathbf{n = 2 1 )}\end{array}$ & $\begin{array}{l}\text { Untreated group } \\
(\mathbf{n = 5 2 )}\end{array}$ & $\begin{array}{l}\text { Women with } \\
\text { depression }(\mathbf{n}=\mathbf{7 3})\end{array}$ \\
\hline Major depressive disorder & 18 & 38 & 56 & Period \\
& 0 & 42 & 42 & Pregnancy \\
Pysthymia & 0 & 1 & 1 & Postpartum \\
Minor depression & 0 & 0 & 0 & Postpartum \\
& 3 & 7 & 5 & Pregnancy \\
Double depression & 0 & 5 & 6 & Postpartum \\
Total depression & 0 & 6 & 1 & Pregnancy \\
& 0 & 1 & 73 & Postpartum \\
& 21 & 52 & $48(65.7 \%)$ & Pregnancy \\
\hline
\end{tabular}

Abbreviation: SCID-I, Structured Clinical Interview for DSM-IV Axis I Disorders. 
Table 2 Edinburgh Postpartum Depression Scale, General Health Questionnaire, General Assessment of Functionality, and PSS-Fa scores of treated and untreated groups in the first trimester of pregnancy and the postpartum period

\begin{tabular}{lllll}
\hline Scales or measures & $\begin{array}{l}\text { Treated group } \\
(\mathbf{n = 2 1 )}\end{array}$ & $\begin{array}{l}\text { Untreated group } \\
(\mathbf{n = 5 2 )}\end{array}$ & $\begin{array}{l}\text { P-value (difference } \\
\text { between two groups) }\end{array}$ \\
\hline Edinburgh Postpartum & $15.61 \pm 3.08$ & $18.76 \pm 4.45$ & $<0.05$ & Period \\
Depression Scale & $11.38 \pm 3.82$ & $19.96 \pm 4.63$ & $<0.05$ & Pregnancy \\
General Health Questionnaire & $9.19 \pm 5.83$ & $10.21 \pm 5.04$ & $>0.05$ & Postpartum \\
& $5.71 \pm 3.03$ & $12.62 \pm 4.57$ & $<0.05$ & Pregnancy \\
General Assessment of Functionality & $60.00 \pm 6.70$ & $56.05 \pm 9.25$ & $<0.05$ & Postpartum \\
& N/A & $52.60 \pm 9.39$ & $<0.05$ & Pregnancy \\
PSS-Fa & $20.00 \pm 6.67$ & $18.03 \pm 8.65$ & $>0.05$ & Postpartum \\
& $27.38 \pm 6.11$ & $18.98 \pm 8.70$ & $<0.05$ & Pregnancy \\
\hline
\end{tabular}

Note: Data presented as mean score \pm standard deviation.

Abbreviations: PSS-Fa: Perceived Social Support From Family and Friends Scale - Family Subscale; N/A, not available.

In contrast, the postnatal scores of the treated group were significantly lower when compared to the prenatal scores. The EPDS scores of the treated and untreated groups differed from each other both during pregnancy (before treatment) and during the postnatal period. The EPDS scores of the untreated group were higher $(P>0.05)$ (Table 2).

In the untreated group, the postnatal GHQ scores were significantly higher than during pregnancy $(P<0.05)$. In the treated group, the postnatal GHQ scores were significantly lower than during pregnancy $(P<0.05)$ (Table 2$)$.

GAF scores were lower during pregnancy in the untreated group than in the treated group. In addition, in the untreated group, it was found that GAF scores were significantly lower in the postnatal period than during pregnancy $(P<0.05)$ (Table 2).

While there was no difference in PSS scores between the treated group and untreated group during pregnancy, in the postnatal period, the scores of the treated group were significantly higher when compared to both the untreated group and to pretreatment $(P<0.05)$ (Table 2).

In addition, the study assessed the treatments received by the women in the treated group. Fourteen (66.7\%) received medical treatment alone, five $(23.8 \%)$ received psychotherapy alone (all individual interpersonal psychotherapy conducted by a psychiatrist), and two $(9.5 \%)$ received both medical treatment and psychotherapy. Decisions regarding the treatment process were made according to patient preference and clinical and social conditions. Those who refused to use medication or who were better able to undertake the psychotherapy process (eg, had the time or were close to the health center) were referred to interpersonal psychotherapy. Detailed data about the treatment process are given in Table 3. The study found no statistically significant difference between the treatment models in terms of results.

Likewise, the study found no statistically significant difference between the treated group and the untreated group in

Table 3 Treatment anamnesis of patients with depression during pregnancy

\begin{tabular}{|c|c|c|}
\hline Treatment & Process & Course \\
\hline Interpersonal therapy & $\begin{array}{l}\text { Five patients } \\
\text { Five to } 12 \text { sessions }\end{array}$ & $\begin{array}{l}\text { Remissions reported at the end of the } \\
\text { second and third trimesters of pregnancy. }\end{array}$ \\
\hline $\begin{array}{l}\text { Medicine utilization } \\
\text { Patients tended to decrease or increase the } \\
\text { dosage medication or ceased drugs completely } \\
\text { according to their severity of symptoms; none } \\
\text { preferred to use maintenance therapy }\end{array}$ & $\begin{array}{l}\text { I4 patients } \\
\text { Sertraline alone: five patients ( } 25-50 \mathrm{mg} \text {, } \\
\text { for } 4-27 \text { weeks) } \\
\text { Escitalopram alone: three patients ( } 3-15 \mathrm{mg} \text {, } \\
\text { for 4-27 weeks) } \\
\text { Mirtazapine combined with sertraline in two } \\
\text { patients and with escitalopram in two patients: } \\
7.5-15 \mathrm{mg} / \text { day irregular use } \\
\text { Lorazepam combined with sertraline in two } \\
\text { patients: } 1-3 \mathrm{mg} / \mathrm{g} \text {, irregular use, few days }\end{array}$ & $\begin{array}{l}\text { Remissions reported at the second and } \\
\text { third trimesters of pregnancy. } \\
\text { One patient had prolonged symptoms to } \\
\text { the postpartum period; used sertraline } \\
25-50 \mathrm{mg} \text { during pregnancy to birth } \\
\text { (ceased for } 2 \text { weeks to labor), then utilizec } \\
\text { for } 4 \text { weeks after birth. }\end{array}$ \\
\hline Interpersonal therapy + medicine & $\begin{array}{l}\text { Two patients } \\
\text { Seven and eight sessions of psychotherapy } \\
25 \mathrm{mg} / \mathrm{g} \text { sertraline for } 27 \text { weeks }\end{array}$ & $\begin{array}{l}\text { Complete remission at the median of the } \\
\text { third trimester. }\end{array}$ \\
\hline Total & 21 patients & \\
\hline
\end{tabular}


terms of sociodemographic data, such as age, marital status, occupation, number of children, income status, place of residence, or whether the pregnancy was planned or unplanned $(P<0.05)$.

\section{Discussion}

This study presents the postnatal diagnoses and scores of 73 women who experienced depression during pregnancy. The study found that 21 (28.7\%) of the women sought treatment. Of the women with a major depressive disorder, $32.1 \%$ sought treatment. In a previous study, it has been reported that only $18 \%$ of women who met the criteria for a major depressive disorder during pregnancy sought treatment. ${ }^{23}$ The higher percentage found in this study might have many causes, such as region, social reasons, sample size, and reasons related to study execution. Nevertheless, when assessed in general, it is striking that, although women with depression were referred, only a small percentage of them sought medical treatment.

The study found that the postnatal depression scores of women who sought and received treatment for depression during pregnancy were lower compared to the prenatal period, and none of them were diagnosed with depression postpartum. However, depression was found in $92 \%$ of those who had not sought treatment, and general depression scores in this group were found to have increased in the postnatal compared to the prenatal period. Depression during pregnancy is accepted as the most important risk factor for perinatal depression. ${ }^{12}$ In previous studies, more than $50 \%$ of women who had a depressive disorder during pregnancy also experienced postpartum depression. ${ }^{12,24}$ In addition, women diagnosed with postpartum depression were twice as likely to experience another depressive episode in the following 5 years. ${ }^{25}$ In this study, the postpartum depression percentage was much higher in the untreated group, providing an answer to the question of whether depression during pregnancy should be treated. ${ }^{13}$

This study found that the high EPDS scores of women treated for depression during pregnancy decreased postpartum, while the scores of untreated women increased in the postnatal period. These results suggest that postpartum depression can be prevented by treating depression during pregnancy. They also suggest that there is a risk of more severe depression in the postpartum period if depression during pregnancy is not treated. A limited number of studies have tracked treated and untreated women in this way. An EPDS study by Bowen et al found that, among women depressed during pregnancy, those who were treated had better progress during pregnancy and in the postnatal period. ${ }^{27}$
This study showed that women who did not seek treatment had lower functionality and higher EPDS scores compared to those who sought treatment. This finding does not provide us with clear information, because the sample is small, but the relationship between lower functionality and seeking treatment should be reviewed in subsequent studies. Bowen et al found that pregnant women who did not seek treatment were younger and more stressed. ${ }^{26}$ This study's higher EPDS scores resemble those of Bowen et al's study, but this study could not identify any difference between the groups in terms of age.

In addition, this study used the GHQ to assess the condition of depressive pregnant women and found that the general health condition of treated women improved in the postnatal period, while the GHQ scores of untreated women deteriorated in the postnatal period. This finding is in conformance with findings of another study that mention the negative effects of depression on a mother's health during pregnancy. ${ }^{27}$ This study did not evaluate the treated or untreated groups for parameters such as mode of delivery, incubator use, delivery complications, or birth weight. However, it has been well documented in previous studies that pregnancy depression constitutes a risk not only for the mother's health, but also for that of the baby. ${ }^{3,4}$

While women in the treated and untreated groups had equivalent perceived social support scores during pregnancy, this study found that the perceived social support of treated women increased in the postnatal period. In every area of life, the difference between being depressed and not being depressed can be reflected in familial relationships, social support, and support perception. The negative perspectives and attitudes of depressive individuals make communication difficult, and these interpersonal communication conflicts deepen their depression. ${ }^{28}$ The potential stresses in communication during the period when a pregnant woman becomes a mother and adds a new and important type of communication to her life, mother-baby communication, are known to have negative results for both mother and baby. ${ }^{29}$

A previous natural longitudinal study conducted by Banti et al showed that having a history of previous depression increases twofold the risk of depression in the perinatal period. ${ }^{9}$ Similarly, Kirkan et al showed that a history of depression is a major indicator of postpartum depression. ${ }^{11}$ It has also been indicated that depression during pregnancy is shown to be a significant predictor of postpartum depression. ${ }^{30}$ In this study, the treatment anamnesis of patients was reviewed with their clinical records and reports, which found that patients did not tend to use high doses of medications in a regular pattern. 
They also did not sustain the standard process of psychotherapy. But, despite all these confounding factors and variability of the patients' treatments, all patients experienced symptom remission, so all of the treatments were beneficial. This study's data led to an important finding: increasing social support, semi-structured treatments, or anything that helps patients with depression during pregnancy instead of neglecting it give patients a strong likelihood of well-being.

The small sample size is a limitation of this study, preventing a comparison of treatment models and their results. However, the strengths of this study include the SCID-I evaluation of the same women both during pregnancy and in the postnatal period and the stark differences in the percentages of both the treated and untreated groups regarding depression diagnoses and scores.

This study presents a significant difference in postpartum depression for the untreated and treated groups: 92\% versus $0 \%$, respectively. Furthermore, this is a natural follow-up study, and the data obtained reflect pure observation without intervention. The results of this study show how important treatment of pregnancy depression is in preventing postnatal depression.

\section{Conclusion}

Untreated depression is an important predictor of postpartum depression. Treating depression during pregnancy plays a preventative role in postpartum depression. This study is important because it presents a very striking postpartum depression rate of $92 \%$ in the untreated group versus $0 \%$ in the treated group. Screening tests during pregnancy are important, but, in addition, psychiatric treatment should be provided and strongly encouraged.

\section{Disclosure}

The authors report no conflicts of interest in this work.

\section{References}

1. Bursalioglu FS, Aydin N, Yazici E, Yazici AB. The correlation between psychiatric disorders and women's lives. J Clin Diagn Res. 2013;7(4):695-699.

2. Zuckerman B, Amaro H, Bauchner H, Cabral H. Depressive symptoms during pregnancy: relationship to poor health behaviors. Am J Obstet Gynecol. 1989;160(5 Pt 1):1107-1111.

3. Suri R, Altshuler LA, Mintz J. Depression and the decision to abort. Am J Psychiatry. 2004;161(8):1502.

4. Rifkin-Graboi A, Bai J, Chen H, et al. Prenatal maternal depression associates with microstructure of right amygdala in neonates at birth. Biol Psychiatry. 2013;74(11):837-844.

5. Çalık KY, Aktas S. Depression in pregnancy: prevalence, risk factors and treatment. Psikiyatride Guncel Yaklasimlar - Current Approaches in Psychiatry. 2011;3(1):142-162.

6. Ayvaz S, Hocaoğlu C, Tiryaki A, Ak I. [Incidence of postpartum depression in Trabzon province and risk factors at gestation]. Turk Psikiyatri Derg. 2006;17(4):243-251. Turkish.
7. Gaynes BN, Gavin N, Meltzer-Brody S, et al. Perinatal depression: prevalence, screening accuracy, and screening outcomes. Evid Rep Technol Assess (Summ). 2005;(119):1-8.

8. Pereira PK, Lovisi GM, Pilowsky DL, Lima LA, Legay LF. Depression during pregnancy: prevalence and risk factors among women attending a public health clinic in Rio de Janeiro, Brazil. Cad Saude Publica. 2009;25(12):2725-2736.

9. Banti S, Mauri M, Oppo A, et al. From the third month of pregnancy to 1 year postpartum. Prevalence, incidence, recurrence, and new onset of depression. Results from the perinatal depression-research and screening unit study. Compr Psychiatry. 2011;52(4):343-351.

10. Akçalı Aslan P, Aydin NN, Yazıcı E, Aksoy AN, Kirkan TS, Daloglu GA. Prevalence of depressive disorders and related factors in women in the first trimester of their pregnancies in Erzurum, Turkey. Int $J$ Soc Psychiatry. 2014;60(8):809-817.

11. Kirkan TS, Aydin N, Yazici E, Akçali Aslan P, Acemoglu H, Daloglu AG. The depression in women in pregnancy and postpartum period: a follow-up study. Int J Soc Psychiatry. Epub 2014 Jul 27.

12. Bilszta JL, Gu YZ, Meyer D, Buist AE. A geographic comparison of the prevalence and risk factors for postnatal depression in an Australian population. Aust N Z J Public Health. 2008;32(5):424-430.

13. Chan J, Natekar A, Einarson A, Koren G. Risks of untreated depression in pregnancy. Can Fam Physician. 2014;60(3):242-243.

14. Corapçıoglu A, Aydemir Ö, Yıldız M, Esen A, Köroğlu E. DSM-IV Eksen-I Bozuklukları İçin Yapılandırllmış Klinik Görüşme [Structured Clinical Interview for DSM-IV Axis I Disorders]. Ankara: Hekimler Yayın Birliği; 1999. Turkish.

15. Cox JL, Holden JM, Sagovsky R. Detection of postnatal depression. Development of the 10-item Edinburgh Postnatal Depression Scale. Br J Psychiatry. 1987;150:782-786.

16. Engindeniz AN, Kuey L, Kultur S. Validity and reliability of Turkish version of Edinburgh Postnatal Depression Scale. In: Book of Annual Meeting of Psychiatric Association of Turkey. Ankara: Turkish Psychiatric Association Press; 1996:51-52.

17. Aydin N, Inandi T, Yigit A, Hodoglugil NN. Validation of the Turkish version of the Edinburgh Postnatal Depression Scale among women within their first postpartum year. Soc Psychiatry Psychiatr Epidemiol. 2004;39(6):483-486.

18. Goldberg DP, Hillier VF. A scaled version of the General Health Questionnaire. Psychol Med. 1979;9(1):139-145.

19. Goldberg DP, Williams P. A User's Guide to the General Health Questionnaire. Windsor: NFER-Nelson; 1988.

20. Kilic C, Rezaki M, Rezaki B, et al. General Health Questionnaire (GHQ12 and GHQ28): psychometric properties and factor structure of the scales in a Turkish primary care sample. Soc Psychiatry Psychiatr Epidemiol. 1997;32(6):327-331.

21. Procidano ME, Heller K. Measures of perceived social support from friends and from family: three validation studies. Am J Community Psychol. 1983;11(1):1-24.

22. Eskin M. Reliability of the Turkish version of the Perceived Social Support from Friends and Family scales, Scale for Interpersonal Behavior, and Suicide Probability Scale. J Clin Psychol. 1993;49(4):515-522.

23. Marcus SM. Depression during pregnancy: rates, risks and consequencesMotherisk Update 2008. Can J Clin Pharmacol. 2009;16(1):e15-e22.

24. Heron J, O'Connor TG, Evans J, Golding J, Glover V; ALSPAC Study Team. The course of anxiety and depression through pregnancy and the postpartum in a community sample. J Affect Disord. 2004;80(1):65-73.

25. Lee AM, Lam SK, Sze Mun Lau SM, Chong CS, Chui HW, Fong DY. Prevalence, course, and risk factors for antenatal anxiety and depression. Obstet Gynecol. 2007;110(5):1102-1112.

26. Bowen A, Bowen R, Butt P, Rahman K, Muhajarine N. Patterns of depression and treatment in pregnant and postpartum women. Can $J$ Psychiatry. 2012;57(3):161-167.

27. Sundaram S, Harman JS, Cook RL. Maternal morbidities and postpartum depression: an analysis using the 2007 and 2008 Pregnancy Risk Assessment Monitoring System. Womens Health Issues. 2014;24(4): e381-e388. 
28. Miniati M, Callari A, Calugi S, et al. Interpersonal psychotherapy for postpartum depression: a systematic review. Arch Womens Ment Health. 2014;17(4):257-268.

29. Leonard LG. Depression and anxiety disorders during multiple pregnancy and parenthood. J Obstet Gynecol Neonatal Nurs. 1998;27(3): 329-337.
30. Abdollahi F, Rohani S, Sazlina GS, et al. Bio-psycho-socio-demographic and obstetric predictors of postpartum depression in pregnancy: a prospective cohort study. Iran J Psychiatry Behav Sci. 2014;8(2): 11-21.

\section{Publish your work in this journal}

Neuropsychiatric Disease and Treatment is an international, peerreviewed journal of clinical therapeutics and pharmacology focusing on concise rapid reporting of clinical or pre-clinical studies on a range of neuropsychiatric and neurological disorders. This journal is indexed on PubMed Central, the 'PsycINFO' database and CAS, and is the official journal of The International Neuropsychiatric Association (INA). The manuscript management system is completely online and includes a very quick and fair peer-review system, which is all easy to use. Visit http://www.dovepress.com/testimonials.php to read real quotes from published authors.

Submit your manuscript here: http://www.dovepress.com/neuropsychiatric-disease-and-treatment-journal 